\title{
Antibiose e antixenose de feijão-fava a Zabrotes subfasciatus (Boh.) (Coleoptera: Chrysomelidae: Bruchinae)
}

\section{Antibiosis and antixenosis of lima bean to Zabrotes subfasciatus (Boh.) (Coleoptera: Chrysomelidae: Bruchinae)}

\author{
José Edmir Girão Filho ${ }^{1 *}$, Luiz Evaldo de Moura Pádua', Eliana de Freitas Pessoa1, \\ Paulo Roberto Ramalho Silva'
}

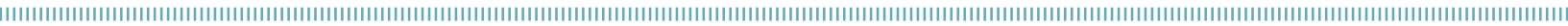

RESUMO: O feijão-fava é uma importante fonte de proteínas e renda para muitas famílias do Nordeste do Brasil. O gorgulho Zabrotes subfasciatus é uma das principais pragas de feijão-fava armazenado, causando prejuízos quantitativos e qualitativos. A resistência genética é uma das formas mais promissoras para o controle de pragas. Dessa forma, esta pesquisa teve o objetivo de estudar e caracterizar os tipos e os níveis de resistência genética de oito acessos de feijão-fava ao ataque de $Z$. subfasciatus. Os ensaios foram realizados em laboratório com temperatura e luminosidade controladas, em delineamento inteiramente casualizado, utilizando os acessos UFPI 230, UFPI 264, UFPI 271, UFPI 515, UFPI 468, UFPI 220, UFPI 280 e UFPI 134 como tratamentos. Foram realizados dois testes: sem chance de escolha e com livre chance de escolha. Houve diferenças significativas para número de ovos, insetos emergidos e mortalidade larval/pupal no teste com livre escolha por meio dos testes F e de Scott-Knott a 5\% de probabilidade. Os índices de atratividade e de preferência para oviposiçáo revelaram que existem diferentes níveis de resistência do tipo não preferência para oviposição. Todos os acessos apresentaram um nível baixo de antibiose. Os acessos UFPI 220, UFPI 468, UFPI 264, UFPI 134 e UFPI 230 apresentaram resistência por antixenose quando comparados com UFPI 515. O acesso UFPI 515 foi o mais suscetível.

PALAVRAS-CHAVE: teste sem escolha; teste com livre escolha; grãos armazenados; Phaseolus lunatus.

\begin{abstract}
Lima bean is an important source of protein and income for many families in Northeast Brazil. Zabrotes subfasciatus is the main pest of stored lima bean, which is responsible for quantitative and qualitative losses. Genetic resistance is one of the most promising ways to control pests. Thus, this research aimed to study the genetic resistance of eight accessions of lima bean to $Z$. subfasciatus attack. Assays were performed in the laboratory with temperature and lighting controlled in a completely randomized design using the UFPI 230, UFPI 264, UFPI 271, UFPI 515, UFPI 468, UFPI 220, UFPI 280, and UFPI 134 accessions as treatments. No-choice and free-choice tests were performed. In the free-choice test significant differences were observed in the number of eggs, emerged insects and larval/pupal mortality using the F test and Scott-Knot, both at $5 \%$ of probability. The attractivity and preference indicators for oviposition have shown that there are different resistance levels of no preference type for oviposition. All accessions revealed a low antibiosis level. The UFPI 220, UFPI 468, UFPI264, UFPI 134, and UFPI 230 accessions presented antixenosis resistance when compared to the UFPI 515 accession. The UFPI 515 was the most susceptible.
\end{abstract}

KEYWORDS: no-choice test; free-choice test; stored grain; Phaseolus lunatus. 


\section{INTRODUÇÃO}

A regiáo Nordeste é a maior produtora de feijão-fava (Phaseolus lunatus L.) do Brasil, contribuindo com 96,56\% da produção do País, destacando-se os estados do Ceará, da Paraíba, de Pernambuco, do Piauí, do Rio Grande do Norte e do Maranháo, em ordem decrescente de produção. A quantidade de feijáo-fava produzida no Brasil, no período de 2012 a 2014, aumentou, mesmo com uma redução da área colhida, representando um aumento na produtividade da cultura. Em 2012, houve variaçáo de 136 a 2.037 kg.ha ${ }^{-1}$ nos estados da Paraíba e do Rio Grande do Sul, respectivamente; já em 2014, os valores oscilaram de 261 a 2.615 kg.ha ${ }^{-1}$ nos estados de Minas Gerais e do Rio Grande do Sul, respectivamente (IBGE, 2014). A grande discrepância nessa produtividade pode ser atribuída às características socioculturais dos agricultores familiares das regiōes Nordeste e Sul do Brasil, visto que Alves et al. (2008) encontraram produtividades de $3.500 \mathrm{~kg} \cdot \mathrm{ha}^{-1} \mathrm{em}$ um experimento no estado da Paraíba.

Zabrotes subfasciatus (Boh.) é uma das principais pragas do feijão armazenado, distribuindo-se nas Américas Central e do Sul, na África, no Mediterrâneo e na Índia (Oliveira; Vendramim, 1999). A infestação pode ocorrer com a planta ainda no campo. A fêmea penetra na vagem e oviposita no grão. Em condições favoráveis, a larva eclode, penetra no grão, alimenta-se e, ao emergir, deixa um orifício nele, ocasionando perdas fisiológicas e sanitárias que podem inviabilizar o uso ou a comercializaçáo do produto (Baldin; Pereira, 2010; GALLO et al., 2002).

A fim de reduzir o uso de produtos químicos nos grãos armazenados, reconhecidamente tóxicos e de delicada manipulação por parte dos aplicadores, a resistência genética tem sido bastante estudada (Giráo Filho et al., 2012; Baldin; Pereira, 2010; Mazzonetto; Boiça Júnior, 1999; Lara, 1991).

Devido às pesquisas realizadas com Phaseolus vulgaris com a finalidade de buscar resistência a pragas, já é possível conhecer alguns genótipos resistentes tanto a $Z$. subfasciatus como a Bemisia tabaci, bem como algumas proteínas que lhes conferem tal resistência (Baldin; Pereira, 2010; Oriani et al., 2005). De acordo com Gallo et al. (2002), a resistência genética, pela fácil aplicação, é a forma mais promissora de controle de pragas e doenças, por ser compatível com qualquer outro método, sem contaminaçáo do produto e sem custos adicionais ao produtor. Entretanto, o feijão-fava náo possui um programa de melhoramento táo consistente como o do feijáo comum, o que torna muito difícil a obtençấo de informaçôes a respeito das relações entre feijão-fava e insetos. Por esse motivo, esta pesquisa teve o objetivo de estudar e caracterizar os tipos e os níveis de resistência genética de oito acessos de feijão-fava ao ataque do gorgulho $Z$. subfasciatus.

\section{MATERIAL E MÉTODOS}

Os ensaios foram conduzidos no Laboratório de Fitossanidade do Departamento de Fitotecnia do Centro de Ciências Agrárias da Universidade Federal do Piauí (UFPI), localizada no município de Teresina (PI), durante o período de agosto de 2010 a junho de 2011.

A pesquisa foi dividida em duas etapas: na primeira, foi realizado o teste sem chance de escolha, na segunda, o teste com chance de escolha, ambos mantidos em temperatura controlada de $29 \pm 2^{\circ} \mathrm{C}$ e fotofase de 12 horas.

Os tratamentos foram constituídos pelos acessos de feijáofava UFPI 230, UFPI 264, UFPI 271, UFPI 515, UFPI 468, UFPI 220, UFPI 280 e UFPI 134, oriundos do Banco Ativo de Germoplasma de Feijão-Fava da Universidade Federal do Piauí (BAGF/UFPI).

Objetivando a multiplicação da população dos insetos, adultos de $Z$. subfasciatus foram coletados em sementes de feijão-fava armazenadas no BAGF/UFPI e acondicionados em depósito plástico com capacidade para $5 \mathrm{~L}$ contendo grãos de feijão-fava adquiridos no mercado municipal, até que houvesse populaçáo suficiente para a montagem dos ensaios. Para a instalação dos ensaios, utilizaram-se insetos com 0 a 24 horas de emergido. No teste sem chance de escolha, utilizaram-se dez repetiçóes, cada uma composta por dez grãos de feijão-fava e um casal de $Z$. subfasciatus, acondicionados em recipientes plásticos de $5 \mathrm{~cm}$ de diâmetro por $6 \mathrm{~cm}$ de altura. Após sete dias de confinamento em contato com seus respectivos hospedeiros, os insetos foram retirados e descartados. No $15^{\circ}$ dia após a infestação, efetuou-se a contagem dos ovos viáveis; decorridos 20 dias da instalação do teste, as observações passaram a ser diárias, a fim de quantificar e descartar os insetos recém-emergidos. A parcela que durante três dias consecutivos não emergia inseto algum era descartada.

Consideraram-se ovos viáveis aqueles de cor branca leitosa e inviáveis aqueles transparentes (RibEIRo-Costa et al., 2007).

A antixenose foi avaliada por meio do teste com livre chance de escolha (Girão Filho, et al., 2012; Mazzonetto; BoIÇA JúNIOR, 1999), que se constitui de um recipiente central, onde são colocados os insetos, e outros recipientes periféricos equidistantes, onde são colocados os grãos (tratamentos). Cada recipiente periférico é interligado ao central por tubos de $12 \mathrm{~cm}$, confeccionados com mangueira de $3 \mathrm{~mm}$ de diâmetro. Utilizaram-se cinco arenas, as quais constituíram as repetiçóes desse teste.

Foram colocados no compartimento central de cada arena 32 casais de $Z$. subfasciatus com 0 a 24 horas de emergidos. Após 24 horas da liberação dos insetos, as tubulaçôes de passagem aos acessos de feijão-fava foram bloqueadas. Os insetos permaneceram confinados no tratamento escolhido durante sete dias, sendo posteriormente retirados, quantificados e descartados. 
Os parâmetros avaliados nesta pesquisa foram: número de ovos viáveis, mortalidade larval/pupal (Número de ovos viáveis - número de insetos emergidos), emergência de adultos, período médio de desenvolvimento (PMD) (RibeiroCosta et al., 2007) (Equação 1), número de insetos atraídos, índice de atratividade (IA) (BALdIN; LARA, 2001) (Equação 2) e índice de preferência para oviposição (IPO) (FEnEMORE, 1980) (Equação 3).

$$
\mathrm{PMD}=\frac{\begin{array}{c}
\sum \text { dias de emergência } \mathrm{x} \\
\text { número de insetos emergidos }
\end{array}}{\sum \text { insetos emergidos }-3,5^{*}}
$$

Onde:

* = metade do período de confinamento.

$$
I A=\frac{2 G}{(G+P)}
$$

Onde:

IA = índice de atratividade;

$\mathrm{G}=$ total insetos atraídos por acesso;

$\mathrm{P}=$ total de insetos atraídos para o acesso padrão, indicado a partir do teste sem chance de escolha.

Os valores de IA variam entre zero e dois, sendo que IA = 1 indica atração semelhante entre o acesso avaliado e o padrão, IA > 1 indica maior atração pelo acesso avaliado em relação ao padrão e IA < 1 corresponde à menor atração. Utilizou-se o erro padrão da média para classificar os acessos em "mais atrativos", "menos atrativos" ou "neutros" em relação ao acesso padrão (BALDIN; LARA, 2001).

$$
\mathrm{IPO}=\left[\frac{(\mathrm{G}-\mathrm{P})}{(\mathrm{G}+\mathrm{P})}\right] \times 100
$$

Onde:

IPO = índice de preferência para oviposição;

$\mathrm{G}=$ número total de ovos viáveis nos acessos a serem testados; $\mathrm{P}=$ número total de ovos no acesso considerado padrão.

O IPO pode variar de 100 (muito estimulante) a -100 (total deterrência ou inibição de oviposição).

Os materiais foram classificados comparando-se os índices obtidos no acesso avaliado e no acesso padrão mais ou menos o erro padrão $(\mathrm{EP})$ da média, para sua diferenciação (BALdin; LARA, 2001).

Escolheu-se o acesso UFPI 515 como padrão (suscetível) para as comparaçóes realizadas no teste com livre chance de escolha, como sugerido por GirÃo FilHo et al. (2012) e por apresentar comportamento semelhante ao verificado por esses autores.
Para as análises estatísticas, utilizou-se o software Assistat $7.7^{\oplus}$. Os dados relativos ao número de ovos viáveis do teste de confinamento e ao PMD do teste com livre chance de escolha não foram transformados para as análises estatísticas, pois eles apresentavam-se normais segundo os testes de KolmogorovSmirnov e Shapiro-Wilk. No entanto, para os parâmetros do teste com livre chance de escolha (número de ovos viáveis, insetos emergidos, mortalidade de fases imaturas e insetos atraídos), os dados foram transformados em $\sqrt{x+0,5}$, para obtenção da normalidade segundo os testes já mencionados. Os dados foram submetidos à análise de variância (teste F); quando necessário, foi aplicado o teste de Scott-Knott para comparação das médias, ambos a 5\% de probabilidade.

\section{RESULTADOS E DISCUSSÃO}

Não houve diferenças significativas entre os tratamentos para número de ovos por fêmea no teste de confinamento (Tabela 1). Segundo Mazzonetto; BoiçA Júnior (1999), isso mostra boa uniformidade, o que é importante para a identificação de resistência. Esses resultados são similares aos encontrados por SAntos et al. (2010) e Girão Filho et al. (2012), os quais, trabalhando com P. lunatus, também não observaram diferenças estatísticas quanto ao número de ovos por fêmea. Isso pode indicar que nenhum dos acessos testados apresentou estímulos negativos à oviposição de $Z$. subfasciatus quando em confinamento. Nesse caso, uma resistência antibiótica seria muito importante, pois poderia fazer a diferença na quantidade de adultos emergidos na geração seguinte e, consequentemente, no índice de infestação.

Em relação à emergência de insetos adultos, os dados variaram de 82,29\% (no acesso UFPI 220) a 97,61\% (no acesso UFPI 134) (Tabela 1). GirÁo Filho et al. (2012), trabalhando com $Z$. subfasciatus e $P$. lunatus, encontraram percentuais de 79,21\% (no acesso UFPI 515) e 92,74\% (no UFPI 494). SANTOS et al. (2010), trabalhando com os acessos de feijāo-fava UFPI-468, UFPI-220, UFPI-515 e UFPI579, não encontraram diferenças significativas entre eles para emergência de $Z$. subfasciatus. Esses resultados demonstram a uniforme suscetibilidade que há entre os acessos de feijão-fava testados até o momento em relação à antibiose. Em contrapartida, para o feijão-carioca (P. vulgaris), já foram observadas emergências de apenas 13,4\% (Ribeiro-Costa et al., 2007) e 53,4\% (Mazzonetto; BoiçA Júnior, 1999). Da mesma forma, na mortalidade em fases imaturas, a maior taxa foi observada no acesso UFPI 220, com $17,71 \%$, e a menor, no acesso UFPI 134, com 2,39\%. Ribeiro-Costa et al. (2007) e MazzonetTo; BoiçA Júnior (1999) observaram, respectivamente, mortalidade de 86,6 e 46,6\% em feijão-carioca em decorrência de $Z$. subfasciatus. Essa alta antibiose encontrada por esses autores está relacionada com proteínas do grupo das 
lectinas, chamadas de Arcelina (Osborn et al., 1988), que estáo presentes nos grãos de $P$. vulgaris e impedem que o inseto utilize o amido do grão em seu intestino, causando a sua morte.

O PMD dos insetos variou de 32,67 dias (no acesso UFPI 280 ) a 34,42 dias (no acesso UFPI 264) no teste de confinamento (Tabela 1), um pouco acima dos valores encontrados por SANTOS et al. (2010), que reportaram PMD entre $28 \mathrm{e}$ 30 dias, e Girâo FilHo et al. (2012), que encontraram valores variando de 29 a 30 dias. Essa diferença pode estar relacionada com a temperatura, devido à sua grande influência nesse parâmetro (Gallo et al., 2002). Por outro lado, Ribeiro-Costa et al. (2007) observaram, no genótipo Arc 1, um PMD de $Z$. subfasciatus de 41,7 dias com P. vulgaris. Segundo Lara (1991), esse tipo de efeito sobre a vida dos insetos pode manter a praga abaixo do nível de dano econômico sem onerar os custos, o que faz da resistência genética uma ferramenta excepcional no controle de pragas. Esse alongamento no período de desenvolvimento do inseto confere ao genótipo um número menor de ciclos da praga em um determinado período de armazenamento, podendo gerar um número de insetos menor, quando comparado com um genótipo sem essa característica.

Em relaçáo à antixenose, observada pelo teste com livre chance de escolha, percebeu-se que os acessos UFPI 220, UFPI 468, UFPI 264 e UFPI 230 foram os menos ovipositados, diferindo dos demais e igualando-se entre si. Os acessos UFPI 271, UFPI 134, UFPI 515 e UFPI 280 foram os mais ovipositados, sendo estatisticamente iguais entre si (Tabela 2). Esse fato provavelmente está associado à atratividade dos respectivos acessos, visto que o número de insetos atraídos para os respectivos tratamentos segue o mesmo padrão da quantidade de ovos postos (Tabela 3), isto é, o acesso mais atrativo foi o mais ovipositado. Dessa forma, os acessos testados podem ser agrupados

Tabela 1. Médias de dez repetições; ovos por fêmea e insetos emergidos. Percentual de mortalidade de fases imaturas e período médio de desenvolvimento em teste sem chance de escolha entre $Z$. subfasciatus e $P$. lunatus.

\begin{tabular}{lcccc}
\hline $\begin{array}{c}\text { Acessos/ } \\
\text { tratamentos }\end{array}$ & $\begin{array}{c}\text { Ovos por } \\
\text { fêmea }\end{array}$ & $\begin{array}{c}\text { Insetos } \\
\text { emergidos* }\end{array}$ & $\begin{array}{c}\text { Mortalidade de } \\
\text { fases imaturas (\%)* }\end{array}$ & $\begin{array}{c}\text { PMD } \\
\text { (dias)* }\end{array}$ \\
\hline UFPI 220 & 17,5 & 14,4 & 17,71 & 33,29 \\
\hline UFPI 468 & 13,3 & 11,1 & 16,54 & 33,87 \\
\hline UFPI 264 & 15,9 & 13,7 & 13,84 & 34,42 \\
\hline UFPI 271 & 21,0 & 19,3 & 8,10 & 33,01 \\
\hline UFPI 134 & 20,9 & 20,4 & 2,39 & 32,97 \\
\hline UFPI 515 & 21,8 & 19,7 & 9,63 & 32,99 \\
\hline UFPI 280 & 20,8 & 17,8 & 14,42 & 32,67 \\
\hline UFPI 230 & 18,8 & 15,7 & 14,21 & 34,21 \\
\hline F & 0,8218 n.s. & & & \\
\hline CV (\%) & 55,89 & & & \\
\hline
\end{tabular}

n.s.: não significativo para o teste $\mathrm{F}$ a $5 \%$ de probabilidade; PMD: período médio de desenvolvimento; *Dados não analisados estatisticamente.

Tabela 2. Médias de cinco repetições; número de ovos, insetos emergidos e período médio de desenvolvimento. Percentual de mortalidade de fases imaturas, em teste com livre chance de escolha de $Z$. subfasciatus e $P$. lunatus.

\begin{tabular}{lcccc} 
Tratamentos & $\begin{array}{c}\text { Número de } \\
\text { ovos }\end{array}$ & $\begin{array}{c}\text { Insetos } \\
\text { emergidos }\end{array}$ & $\begin{array}{c}\text { Mortalidade de } \\
\text { fases imaturas (\%) }\end{array}$ & PMD \\
\hline UFPI 220 & $57,0 \mathrm{~b}$ & $47,8 \mathrm{~b}$ & $9,2 \mathrm{~b}$ & $32,84 \mathrm{a}$ \\
\hline UFPI 468 & $41,2 \mathrm{~b}$ & $36,6 \mathrm{~b}$ & $4,6 \mathrm{~b}$ & $34,42 \mathrm{a}$ \\
\hline UFPI 264 & $57,8 \mathrm{~b}$ & $49,2 \mathrm{~b}$ & $8,6 \mathrm{~b}$ & $35,68 \mathrm{a}$ \\
\hline UFPI 271 & $82,0 \mathrm{a}$ & $74,6 \mathrm{a}$ & $7,4 \mathrm{ab}$ & $33,74 \mathrm{a}$ \\
\hline UFPI 134 & $89,6 \mathrm{a}$ & $80,6 \mathrm{a}$ & $9,0 \mathrm{~b}$ & $33,87 \mathrm{a}$ \\
\hline UFPI 515 & $114,2 \mathrm{a}$ & $93,2 \mathrm{a}$ & $21,0 \mathrm{a}$ & $32,54 \mathrm{a}$ \\
\hline UFPI 280 & $112,2 \mathrm{a}$ & $94,6 \mathrm{a}$ & $17,6 \mathrm{a}$ & $33,47 \mathrm{a}$ \\
\hline UFPI 230 & $52,4 \mathrm{~b}$ & $43,2 \mathrm{~b}$ & $9,2 \mathrm{~b}$ & $34,72 \mathrm{a}$ \\
\hline F & $2,54^{*}$ & $2,25 *$ & $2,61 *$ & $1,44^{\text {n.s. }}$ \\
\hline CV (\%) & 27,09 & 28,43 & 35,21 & 6,25 \\
\hline
\end{tabular}

Médias seguidas de mesma letra na coluna não diferem estatisticamente entre si pelo teste de Scott-Knott a $5 \%$ de probabilidade.

n.s.: não significativo para o teste $\mathrm{F}$ a $5 \%$ de probabilidade; PMD: período médio de desenvolvimento; ${ }^{*} \mathrm{p}<0,05$. 
Tabela 3. Médias dos insetos atraídos, índice de atratividade \pm erro padrão da média, classificação, índice de preferência para oviposição \pm erro padrão da média e classificação em teste com livre chance de escolha entre $Z$. subfasciatus e feijão-fava.

\begin{tabular}{|c|c|c|c|c|c|}
\hline Tratamentos & $\begin{array}{c}\text { Número de } \\
\text { insetos atraídos }\end{array}$ & IA & Classe & IPO & Classe \\
\hline UFPI 220 & $5,6 b$ & $0,636 \pm 0,05$ & - & $-33,41 \pm 6,58$ & - \\
\hline UFPI 468 & $5,4 b$ & $0,621 \pm 0,05$ & - & $-46,97 \pm 6,58$ & - \\
\hline UFPI 264 & $6,4 b$ & $0,696 \pm 0,05$ & - & $-32,79 \pm 6,58$ & - \\
\hline UFPI 271 & $10,6 a$ & $0,938 \pm 0,05$ & - & $-4,42 \pm 6,58$ & $\mathrm{~N}$ \\
\hline UFPI 134 & 10,2 a & $0,919 \pm 0,05$ & - & $-12,07 \pm 6,58$ & - \\
\hline UFPI 515 & $12,0 \mathrm{a}$ & $1 \pm 0,05$ & Padrão & $0 \pm 6,58$ & Padrão \\
\hline UFPI 280 & $11,2 \mathrm{a}$ & $0,966 \pm 0,05$ & $\mathrm{~N}$ & $-0,88 \pm 6,58$ & $\mathrm{~N}$ \\
\hline UFPI 230 & $6,2 \mathrm{~b}$ & $0,681 \pm 0,05$ & - & $-37,09 \pm 6,58$ & - \\
\hline $\mathrm{F}$ & $3,46^{* *}$ & & & & \\
\hline CV (\%) & 18,77 & & & & \\
\hline
\end{tabular}

Médias seguidas de mesma letra na coluna não diferem estatisticamente pelo teste de Tukey a $5 \%$.

IA: índice de atratividade: IPO: índice de preferência para oviposição; **p<0,01.

em menos ou mais atrativos à oviposição. GirÃo FilHo et al. (2012) sugeriram o acesso UFPI 515 como padrão de suscetibilidade, sendo o acesso mais atrativo e preferido entre os estudados, fato também confirmado nesta pesquisa.

Em relação ao número de insetos emergidos, podemos observar o mesmo padrão descrito, em que há uma tendência de que o acesso mais ovipositado tenha uma maior emergência; tal fato revela que não há uma antibiose acentuada, como no caso relatado por Ribeiro-Costa et al., (2007) e BALdin; Pereira (2010), em que os genótipos que apresentam arcelina proporcionam uma menor quantidade de insetos emergidos, mesmo havendo igualdade na postura.

A mortalidade larval/pupal variou de 4,6\% (no acesso UFPI 468) a 21\% (no UFPI 515). Girâo FilHo et al. (2012) também observaram que o acesso UFPI 515, em teste sem chance de escolha, apresentou uma mortalidade semelhante, $20 \%$; no entanto, esse comportamento não se repete nos testes de confinamento, o que pode ser uma pseudorresistência influenciada pela quantidade de insetos atraídos e pela quantidade de ovos postos.

Em relação ao IA, podemos observar que, exceto o acesso UFPI 280, que foi classificado como tendo a mesma atratividade que o acesso padrão, os demais foram menos atrativos que o padrão UFPI 515 (Tabela 3).

Da mesma forma que no IA, também observamos somente dois tipos de comportamento em relação ao padráo quando aplicamos o IPO: os acessos UFPI 271 e UFPI 280 foram igualmente preferidos, e os acessos UFPI 220, UFPI 468, UFPI 264, UFPI 134 e UFPI 230 foram menos preferidos para oviposição.

Girâo Filho et al. (2012) constataram que o acesso UFPI 515, além de ser mais atrativo que os demais, foi também o mais susceptível em relação à preferência para oviposição. Ainda de acordo com os mesmos autores, verificou-se, nesta pesquisa, que o acesso UFPI 468 continuou a se comportar como resistente em relaçáo ao padráo em teste com livre chance de escolha, apresentando indícios de resistência do tipo não preferência para oviposição e sendo, portanto, sugerido para testes posteriores com comparaçóes entre outros acessos. Por outro lado, o acesso UFPI 220 não se comportou da mesma maneira. Esse acesso, que teria sido apresentado como sendo um dos mais susceptíveis outrora por esses mesmos autores, agora se apresenta como um dos menos ovipositados, menos atrativos e menos preferidos para oviposição. Dessa forma, sugere-se que novos testes sejam realizados comparando esses acessos com outros, a fim de observar se esse comportamento se repete.

\section{CONCLUSÃO}

Os acessos estudados apresentaram baixos níveis de antibiose. Os acessos UFPI 220, UFPI 468, UFPI 264, UFPI 134 e UFPI 230 apresentaram resistência por antixenose, quando comparados com UFPI 515. Pode-se caracterizar a resistência dos acessos UFPI 220, UFPI 468, UFPI 264, UFPI 134 e UFPI 230 como não preferência para oviposição. Os acessos UFPI 515 e UFPI 280 podem ser considerados os mais susceptíveis entre os acessos testados.

\section{AGRADECIMENTO}

Agradecemos ao Conselho Nacional de Desenvolvimento Científico e Tecnológico (CNPq) pela concessão da bolsa ao primeiro autor. 
ALVES, A.U.; OLIVEIRA, A.P.; ALVES, A.U.; DORNELAS, C.S.M.; ALVES, E.U.; CARDOSO, E.A.; OLIVEIRA, A.N.P.; CRUZ, I.S. Lima beans production and economic revenue as function of organic and mineral fertilization. Horticultura Brasileira, v.26, n.2, p. 251-254, 2008.

BALDIN, E.L.L.; LARA, F.M. Atratividade e consumo foliar por adultos de Diabroticaspeciosa (Germ.) (Coleoptera: Chrysomelidae) em diferentes genótipos de abóbora. Neotropical Entomology, v.30, n.4, p.675-679, 2001.

BALDIN, E.L.L.; PEREIRA, J.M. Resistência de genótipos de feijoeiro a Zabrotes subfasciatus (Bohemann, 1833) (Coleoptera: Bruchidae). Ciência Agrotecnologia, v.34, n.6, p.1507-1513, 2010.

FENEMORE, P.G. Oviposition of potato tuber moth, Phthorimaea operculella Zell. (Lepdóptera: Gelechiidae); Identification of hostplant factors influencing oviposition response. New Zealand Journal of Zoology, v.7, n.3, p.435-439, 1980.

GALLO, D.; NAKANO, O.; SILVEIRA NETO, S.; BAPTISTA, G. C.; BERTI FILHO, E.; PARRA, J.R.P.; ZUCCHI, R.A.; ALVES, S.B.; VENDRAMIM, J. D.; MARCHINI, L. C.; LOPES, J.R.S.; OMOTO, C. Manual de Entomologia Agrícola. Piracicaba: FEALQ, 2002. 920p.

GIRÃO FILHO, J.E.; PÁDUA, L.E.M.; SILVA, P.R.R.; GOMES, R.L.F.; PESSOA, E.F. Resistência genética de acessos de feijão-fava ao gorgulho Zabrotes subfasciatus (Boh.) (Coleoptera: Bruchidae). Comunicata Scientiae, v.3, n.2, p.84-89, 2012.

INSTITUTO BRASILEIRO DE GEOGRAFIA E ESTATÍSTICA - IBGE. Produção Agrícola Municipal. 2014. Disponível em: <http://www. sidra.ibge.gov.br/bda/tabela/listabl.asp?z=t\&c $=1612>$. Acesso em: 29 jun. 2016.
LARA, F. M. Princípios de resistência de plantas a insetos. $2^{\mathrm{a}}$ ed. São Paulo: Ícone, 1991. 36p.

MAZZONETTO, F.; BOIÇA JÚNIOR, A.L. Determinação dos tipos de resistência de genótipos de feijoeiro ao ataque de Zabrotes subfasciatus (Boheman, 1833) (Coleoptera: Bruchidae). Anais da Sociedade Entomológica do Brasil, v.28, n.2, p.307-31 1, 1999.

OLIVEIRA, A.M.; VENDRAMIM, J.D. Repelência de óleos essenciais e pós vegetais sobre adultos de Zabrotes subfasciatus (Boh.) (Coleoptera: Bruchidae) em sementes de feijoeiro. Anais da Sociedade Entomológica do Brasil, v.28, n.3, p.549-555, 1999.

ORIANI, M.A.G.; VENDRAMIM, J.D.; BRUNHEROTTO, R. Atratividade e não-preferência para oviposição de Bemisiatabaci (Genn.) biótipo B (Hemiptera: Aleyrodidae) em genótipos de feijoeiro. Neotropical Entomology, v.34, n. 1, p.105-111, 2005.

OSBORN, T.C.; ALEXANDER, D.C.; SAMUEL, S.M.S.; CARDONA, C.; FREDERICK, A.B. Insecticidal activity and lectin homology of arcelin seed protein. Science, v.240, p.207-210, 1988.

RIBEIRO-COSTA, C.S.; PEREIRA, P.R.V.S.; ZUKOVSKI, L. Desenvolvimento de Zabrotes subfasciatus (Boh.) (Coleoptera: Chrysomelidae, Bruchinae) em genótipos de Phaseolus vulgaris L. (Fabaceae) cultivados no Estado do Paraná e contendo arcelina. Neotropical Entomology, v.36, n.4, p.560-564, 2007.

SANTOS, K.M.S.P.; FONTES, L.S.; BARBOSA, D.R.S.; LIMA, E.F.B. Biologia de Zabrotes subfasciatus (Boh.) (Coleoptera: Bruchidae) em diferentes cultivares de fava (Phaseolus lunatus, (L.)). In: CONGRESSO BRASILEIRO DE ZOOLOGIA, 28., 2010, Belém, PA. Resumos. Belém: 2010. p.52. 